\title{
Effects of Didecyldimethylammonium Chloride (DDAC) on Sprague-Dawley Rats after 13 Weeks of Inhalation Exposure
}

\author{
Yong-Soon Kim, Sung-Bae Lee and Cheol-Hong Lim \\ Chronic Inhalation Toxicity Research Center, Chemicals Toxicity Research Bureau, \\ Occupational Safety and Health Research Institute, KOSHA, Daejeon, Korea
}

(Received April 28, 2016; Revised September 19, 2016; Accepted October 7, 2016)

\begin{abstract}
Didecyldimethylammonium chloride (DDAC) is used in many types of biocidal products including tableware, carpets, humidifiers, and swimming pools, etc. In spite of increased chances of DDAC exposure through inhalation, studies on the inhalation toxicity of DDAC are not common even though the toxicity of DDAC might be significantly higher if it were to be administered through routes other than the respiratory system. DDAC aerosols were exposed to Sprague-Dawley rats in whole body exposure chambers for a duration of 13 weeks. The Mass Median Aerodynamic Diameters of the DDAC aerosol were $0.63 \mu \mathrm{m}$, $0.81 \mu \mathrm{m}$, and $1.65 \mu \mathrm{m}$, and the geometric standard deviations were $1.62,1.65$, and 1.65 in the low $(0.11 \pm$ $\left.0.06 \mathrm{mg} / \mathrm{m}^{3}\right)$, the middle $\left(0.36 \pm 0.20 \mathrm{mg} / \mathrm{m}^{3}\right)$ and the high $\left(1.41 \pm 0.71 \mathrm{mg} / \mathrm{m}^{3}\right)$ exposure groups, respectively. Body weight was confirmed to be clearly influenced by exposure to DDAC and mean body weight was approximately $35 \%$ lower in the high $\left(1.41 \pm 0.71 \mathrm{mg} / \mathrm{m}^{3}\right)$ male group and $15 \%$ lower in the high $\left(1.41 \pm 0.71 \mathrm{mg} / \mathrm{m}^{3}\right)$ female group compared to that of the control group. In the bronchoalveolar lavage fluid assay, the levels of albumin and lactate dehydrogenase had no effect on DDAC exposure. The lung weight increased for the middle $\left(0.36 \pm 0.20 \mathrm{mg} / \mathrm{m}^{3}\right)$ and the high $\left(1.41 \pm 0.71 \mathrm{mg} / \mathrm{m}^{3}\right)$ concentrations of the DDAC exposure group, and inflammatory cell infiltration and interstitial pneumonia were partially observed in the lungs of the middle $\left(0.36 \pm 0.20 \mathrm{mg} / \mathrm{m}^{3}\right)$ and the high $\left(1.41 \pm 0.71 \mathrm{mg} / \mathrm{m}^{3}\right)$ exposure groups. However, severe histopathological symptoms, including proteinosis and/or fibrosis, were not found. Based on the results of the changes in the body weight and lung weight, it is considered that the NOAEL (no-observed adverse effect) level for the 13-week exposure duration is $0.11 \mathrm{mg} / \mathrm{m}^{3}$.
\end{abstract}

Key words: Biocide, Didecyldimethylammonium chloride, Inhalation, Sub-chronic

\section{INTRODUCTION}

Didecyldimethylammonium chloride (DDAC) is a representative dialkyl-quaternary ammonium biocide which is included as an active ingredient in many types of products including applications to hard surfaces (floors, tables, toilets, etc.), eating utensils, laundry detergents, carpets, agricultural tools and vehicles, ultrasonic tanks, water storage tanks, swimming pools, cooling water systems $(1,2)$,

Correspondence to: Cheol-Hong Lim, Chronic Inhalation Toxicity Research Center, Chemicals Toxicity Research Bureau, Occupational Safety and Health Research Institute, KOSHA, 339-30 Exporo, Yuseong-gu, Daejeon 34122, Korea

E-mail: limch@kosha.or.kr

This is an Open-Access article distributed under the terms of the Creative Commons Attribution Non-Commercial License (http:// creativecommons.org/licenses/by-nc/3.0) which permits unrestricted non-commercial use, distribution, and reproduction in any medium, provided the original work is properly cited. etc. Products containing DDAC are used for wood preservation and there are also registered uses for fogging agent applications in occupational settings (1). The content ratio of DDAC in various end-use products ranges from 0.08 $80 \%$. The residues from treated surfaces including utensils, countertops, equipment, and appliances can migrate to food and come into contact with treated and rinsed surfaces, resulting in ingestion by humans. Furthermore, not only residential handlers but also occupational handlers can suffer from exposure via the skin (2). Therefore, the main exposure pathways of DDAC was assumed to be through oral or skin pathways. However, DDAC can also be exposed through the respiratory system when used in aerosol form, especially for workers using the product. It has been discovered that biocides similar to DDAC have been used in South Korea to sterilize household humidifiers. In South Korea, humidifiers are intensively used during the dry winter season to provide humidity. This caused prolonged exposure of DDAC in pregnant women, their 
babies, and postpartum women who were being treated in hospitals or indoor facilities became the main victims of exposure to biocides. Unfortunately, this exposure caused an unknown interstitial lung disease that was fatal in some patients $(3,4)$.

Toxicological data on the biocides is available through many different websites (5). However, there is limited toxicological data considered to be adequate for evaluating the effects of the biocides on the human respiratory system because most patients were considered to be exposed to the biocides mainly via oral pathways or through the skin while the inhalation pathway was ignored. While there were a 13-week duration toxicity data report, a reproductive toxicity data report, and even a carcinogenicity data report available regarding DDAC $(2,6)$, there were only a limited amount of reports on the inhalation toxicity. In regards to DDAC, Ohnuma et al. (1) reported that DDAC could cause severe lung damage when administered through the respiratory system. The study administered $150 \mu \mathrm{g} / \mathrm{kg}$ of DDAC via intratracheal instillation and discovered pulmonary damage in mice. A $1,500 \mu \mathrm{g} / \mathrm{kg}$ dose of DDAC caused severe morbidity with pulmonary congestive edema. Intratracheal administering is a helpful system that helps the understanding of the lung damage caused by the particles. However, there is a chance that the toxicity could be overestimated when an excess of particles is administered at once. In our previous 2-week duration inhalation study, it was observed that only a mild inflammation was induced by $0.6 \mathrm{mg} / \mathrm{m}^{3}$ and $3.6 \mathrm{mg} / \mathrm{m}^{3}$ of DDAC exposure. Fibrosis and/or proteinosis were not observed whereas the body weight of the rats significantly decreased when exposed to $3.6 \mathrm{mg} / \mathrm{m}^{3}$ of DDAC (7). In this study, we exposed rats to DDAC for 13 weeks to verify if inflammation, proteinosis and/or even fibrosis might be caused by longer exposure.

\section{MATERIALS AND METHODS}

DDAC aerosol exposure to animals. 5-week-old male and female specific pathogen-free Sprague-Dawley (SD) rats were obtained from the Central Lab Animal Inc. (Seoul, Korea). The rats were exposed to DDAC aerosols after a 2-week acclimation period. During the experimental period, the rats were exposed to DDAC aerosols in whole body inhalation chambers with controlled temperature $\left(23 \pm 2^{\circ} \mathrm{C}\right)$ and humidity $(50 \pm 10 \%)$ settings and a 12 $\mathrm{hr}$ light/dark cycle. The rats were given filtered water and fed a rodent diet (LabDiet 5053, PMI Nutrition, St. Louis, MO, USA) ad libitum. The animals were divided into four categories of 10 rats for each gender. The categories were the control, low $\left(0.11 \pm 0.06 \mathrm{mg} / \mathrm{m}^{3}\right)$, middle $(0.36 \pm 0.20$ $\left.\mathrm{mg} / \mathrm{m}^{3}\right)$ and high $\left(1.41 \pm 0.71 \mathrm{mg} / \mathrm{m}^{3}\right)$ concentration groups. The study was conducted in accordance with guidelines provided by the Institutional Animal Care and Use Committee of Occupational Safety and Health Research Institute
(Republic of Korea) to ensure appropriate animal care conditions were upheld during the research (Approval No.: IACUC-12-05).

DDAC was purchased from Shin won chemtrade Co. Ltd. (Seoul, Korea). DDAC aerosols were produced using mistgenerating equipment (VG-4R, Sibata Co. Ltd., Soka, Japan) in whole body exposure system (SIS-20RG, Sibata Co. Ltd.) by supplying air at a flow rate of $10 \sim 13$ liters per minute. DDAC aerosols in the chamber were sampled with a XAD2 resin tube $(8 \times 110 \mathrm{~mm}, 200 / 400 \mathrm{mg} X A D-2, \mathrm{SKC}, \mathrm{PA}$, USA) and measured with an ion chromatography (Dionex AS50, CA, USA) equipped with an electron capture detector (Agilent 1049A, Waldbronn, Germany). The analytical conditions were $30 \mathrm{mM}$ sulfuric acid acid (>95\%, SigmaAldrich, MO, USA) and acetonitrile (J.T. Baker, Pennsylvania, USA) (3: 7) with IonPac AS7 column (Dionex, Sunnyvale, CA, USA) (8). The particle size distribution of the DDAC aerosols was measured using a portable aerosol spectrometer (Model 1109, GRIMM, Ainring, Germany). During the experimental period, general clinical symptoms including eye, skin, respiration, and movement were observed. Body weight and food consumption were measured once per week. Activity was measured during the final exposure week using an activity monitoring system (Sibata Co. Ltd.) and lung function was measured using a non-invasive, unrestrained plethysmographic (PLY 3123, Buxco, Wilmington, NC, USA) at 3-day, 4-week, and 12-week durations after exposure.

\section{Hematology and bronchoalveolar lavage (BAL) analysis.} All rats were euthanized for blood collection and BAL analysis. Lavages of the lungs were performed five times with $3 \mathrm{~mL}$ of calcium- and magnesium-free phosphate buffered saline (PBS, pH 7.4) after blood was collected from the abdominal aorta. The BAL fluids were centrifuged at 1,500 rpm for 10 min (Hanil Union 32R, Incheon, Korea) and the supernatants were stored at $-80^{\circ} \mathrm{C}$ to conduct an albumin and lactate dehydrogenase ( $\mathrm{LDH})$ assay at a later time. The numbers of the collected cells from the BAL fluid were counted using a veterinary multi-species hematology instrument (Drew Science, Hemavet 850, CT, USA) and the collected cells were centrifuged using a cytocentrifuge (Hanil Cellspin, Incheon, Korea) to conduct differential counts of white blood cells. The centrifuged cells were stained in a Diff-Quick staining solution (Sysmex, Kobe, Japan) and differential counts of macrophages, lymphocytes, and polymorphonuclear leukocytes (PMNs) were conducted by counting approximately 300 cells under a microscope at $100 \times$ magnification. $\mathrm{LDH}$ and albumin in the BAL fluid were measured using a biochemistry analyzer (Toshiba TBA 20FR, Tokyo, Japan).

Blood samples were collected in blood-collecting tubes containing anti-coagulant EDTA and the total white blood cells, neutrophils, lymphocyte, monocyte, eosinophils and 
basophils were counted using a veterinary multi-species hematology instrument (Drew Science, Hemavet 850, CT, USA).

Histopathology. During the necropsy, the lungs were carefully removed and fixed in a $10 \%$ formalin solution containing neutral PBS. These fixed organs were embedded in paraffin, then sectioned, stained with hematoxylin and eosin, and examined under a light microscope at 400x magnification (axioskop 2 plus, Zeiss, Oberkochen, Germany).

Statistical analysis. Results were presented as mean \pm standard deviation. Data was analyzed based on the Dunnett's t-test to determine the differences between the control group and the group exposed to DDAC using the commercial program SigmaPlot 12 (Systat Software Inc., San Jose, CA, USA).

\section{RESULTS}

The mass median aerodynamic diameter (MMAD) and geometric standard deviation (GSD) were $0.63 \mu \mathrm{m}$ and 1.62 , respectively, for the low $\left(0.11 \pm 0.06 \mathrm{mg} / \mathrm{m}^{3}\right)$ group, $0.81 \mu \mathrm{m}$ and 1.65 , respectively, for the middle $(0.36 \pm 0.20$ $\mathrm{mg} / \mathrm{m}^{3}$ ) group, and $1.14 \mu \mathrm{m}$ and 1.65 , respectively, for the
Table 1. Concentrations of didecyldimethylammonium chloride (DDAC) aerosols in the inhalation chambers during the 13-week exposure period

(unit, $\mathrm{mg} / \mathrm{m}^{3}$ )

\begin{tabular}{ccccc}
\hline \hline Method & Control & Low & Middle & High \\
\hline Concentration levels & ND & $0.11 \pm 0.06$ & $0.36 \pm 0.20$ & $1.41 \pm 0.71$
\end{tabular}

Values were presented as mean \pm standard deviation.

ND, Non-detectable.

high $\left(1.41 \pm 0.71 \mathrm{mg} / \mathrm{m}^{3}\right)$ group (Fig. 1). In this study, the MMAD of DDAC aerosols and the GSD values were confirmed to be within the proper range recommended by the OECD (Organization for Economic Cooperation and Development) (13). During the exposure period, the concentration of DDAC for the low, middle, and high groups were $0.11 \pm 0.06 \mathrm{mg} / \mathrm{m}^{3}, 0.36 \pm 0.20 \mathrm{mg} / \mathrm{m}^{3}, 1.41 \pm 0.71 \mathrm{mg} / \mathrm{m}^{3}$, respectively (Table 1 ).

The mean body weight was confirmed to have significantly decreased in the high $\left(1.41 \pm 0.71 \mathrm{mg} / \mathrm{m}^{3}\right)$ group of rats. It was also confirmed that the mean body weight of male rats in the high $\left(1.41 \pm 0.71 \mathrm{mg} / \mathrm{m}^{3}\right)$ group was approximately $35 \%$ lower than that of the control and the body weight of female rats in the high $\left(1.41 \pm 0.71 \mathrm{mg} / \mathrm{m}^{3}\right)$ group was $15 \%$ lower than that of the control group (Fig. 2). Food consumption also decreased in the high $\left(1.41 \pm 0.71 \mathrm{mg} / \mathrm{m}^{3}\right)$
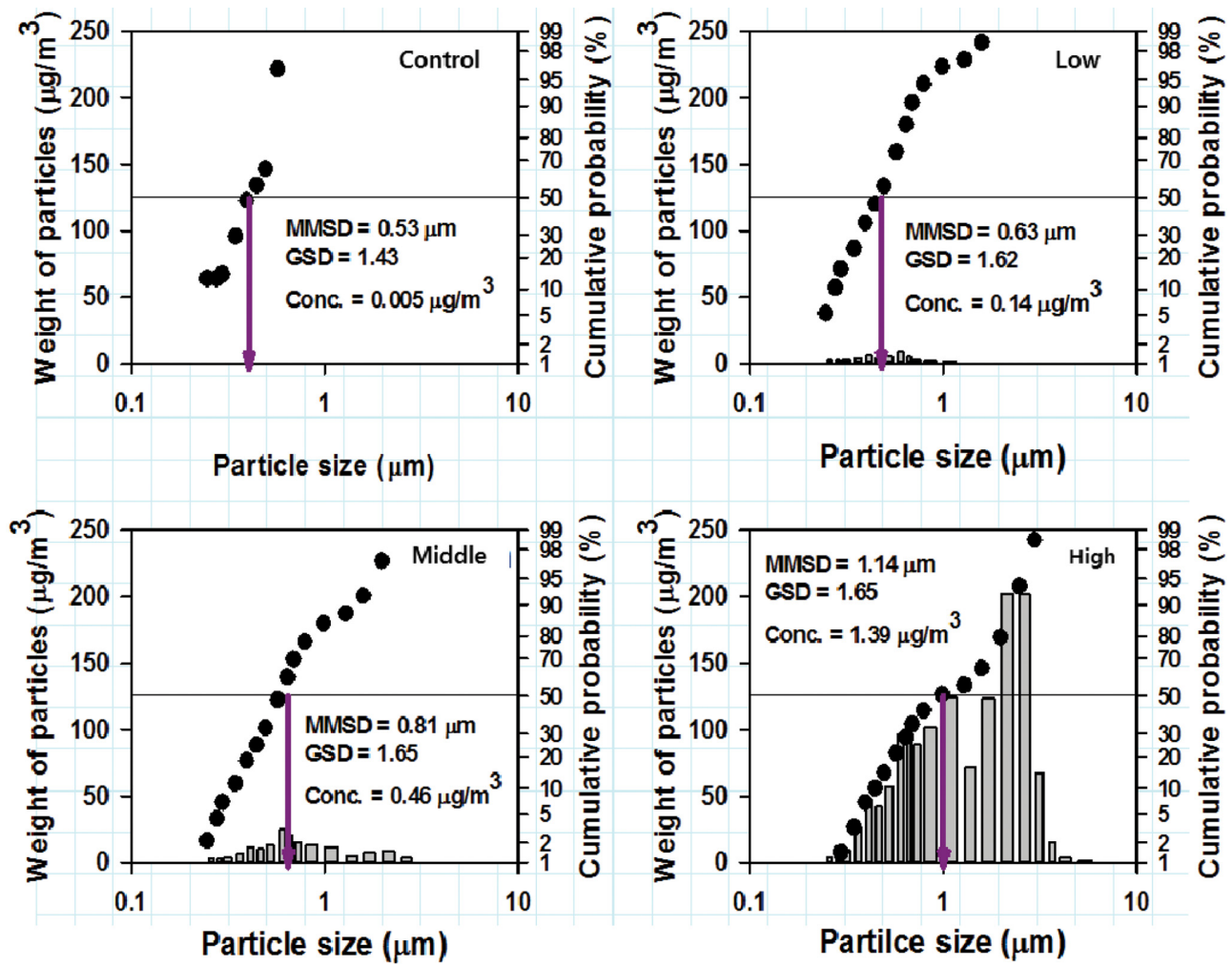

Fig. 1. Particle size distributions of didecyldimethylammonium chloride (DDAC) aerosols in the inhalation chambers. Aerosols were measured using a portable aerosol spectrometer. 


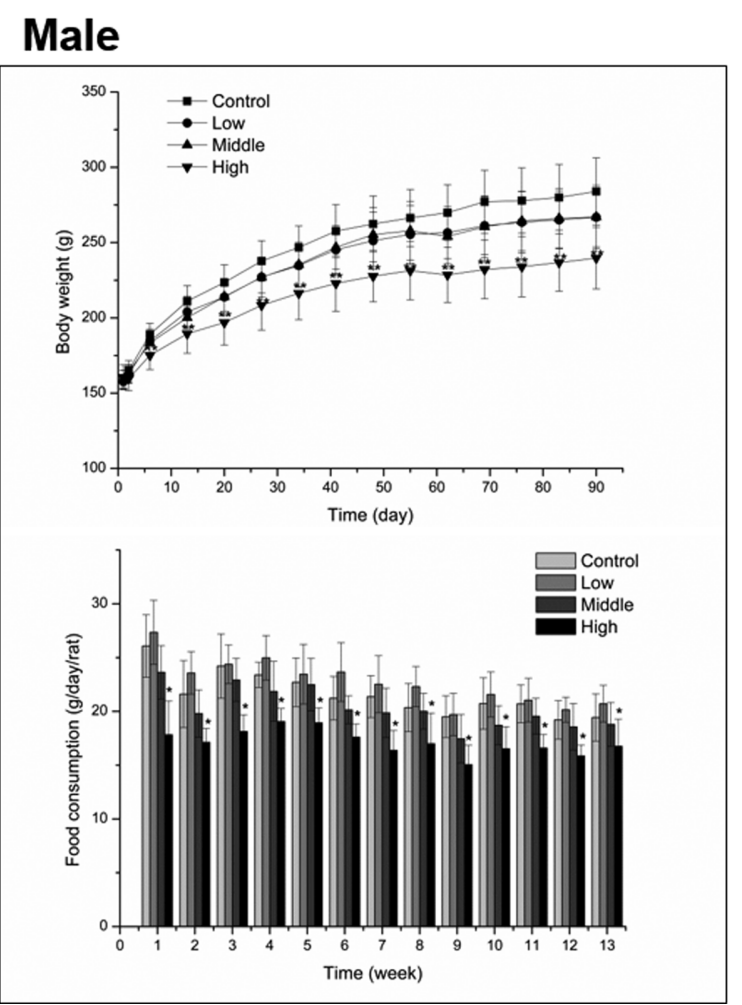

\section{Female}

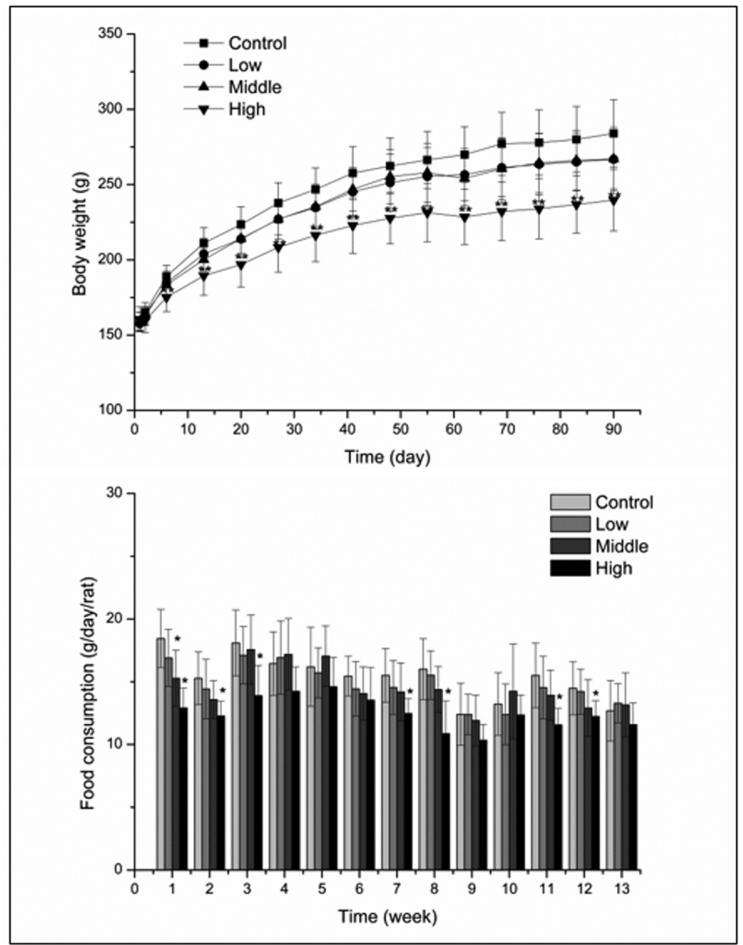

Fig. 2. Effects on the body weight changes (upper panel) and food consumption changes (bottom panel) in didecyldimethylammonium chloride (DDAC) exposed rats during the exposure period. ${ }^{*}$ Significantly different when compared to the control group, $P<0.05$. ** Significantly different when compared to the control group, $P<0.01$.
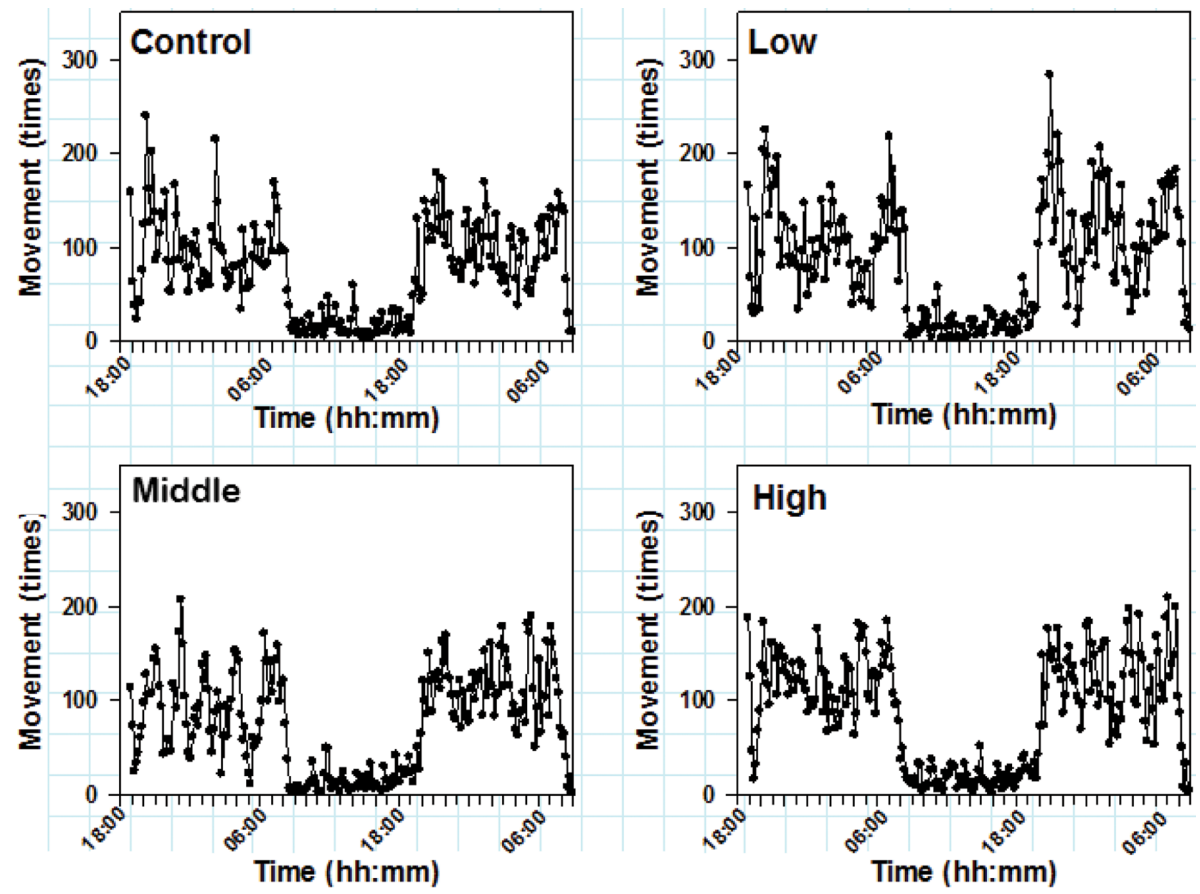

Fig. 3. Effects on the activities in the rats exposed to didecyldimethylammonium chloride (DDAC). Activities were measured over 2 days during the last week of the exposure period. Statistically significant differences were not found between the control group and the rats exposed to DDAC. 

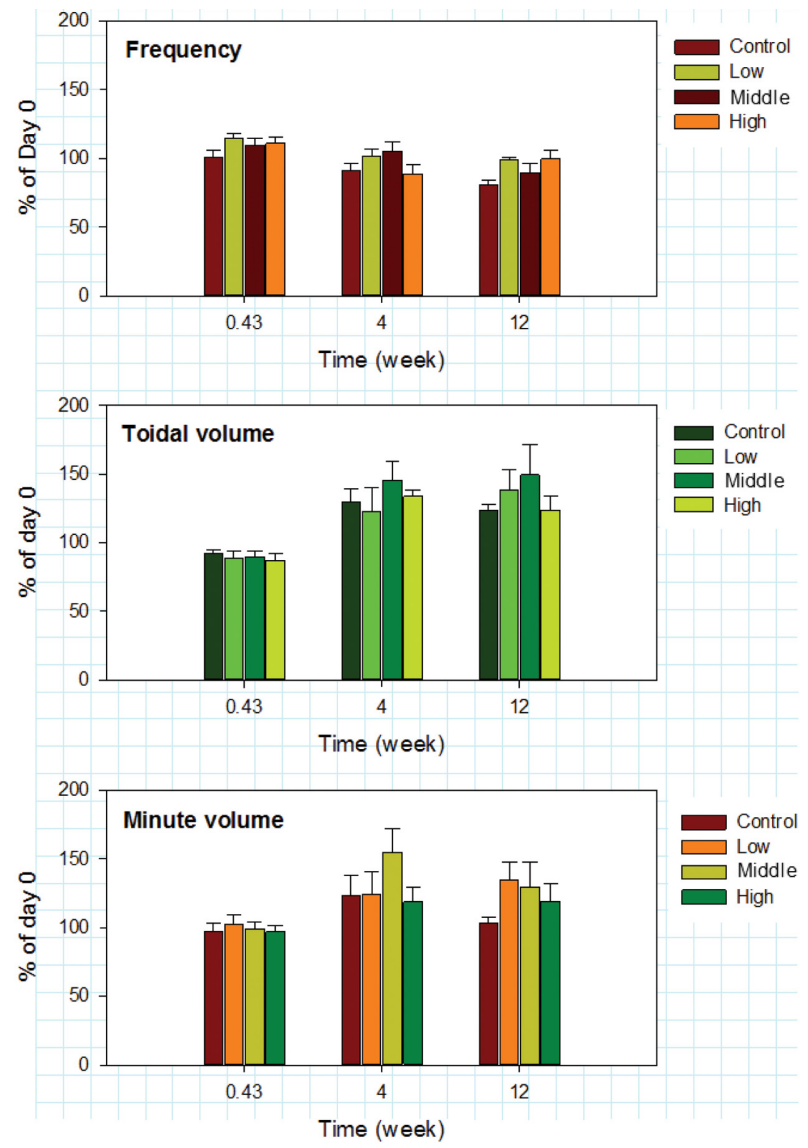

Fig. 4. Effects on the respiratory function in the rats exposed to didecyldimethylammonium chloride (DDAC). Error bars indicate standard error. Statistically significant differences were not found between the control group and the rats exposed to DDAC.

concentration group (Fig. 2).

Other than the change in body weight, the effects of DDAC were confirmed to be relatively minimal and mild. No significant differences were found in the activity levels and respiratory functions of the rats (Fig. 3 and 4). The effects of DDAC on the BAL cell differential count were also mild. The ratios of PMNs increased only to $10 \%$ in the middle $\left(0.36 \pm 0.20 \mathrm{mg} / \mathrm{m}^{3}\right)$ and high $\left(1.41 \pm 0.71 \mathrm{mg} / \mathrm{m}^{3}\right)$ groups and those of the lymphocytes were increased to $7 \%$ at the middle $\left(0.36 \pm 0.20 \mathrm{mg} / \mathrm{m}^{3}\right)$ and high $(1.41 \pm 0.71 \mathrm{mg} /$ $\mathrm{m}^{3}$ ) groups (Fig. 5). Albumin and LDH, which are cell dam-
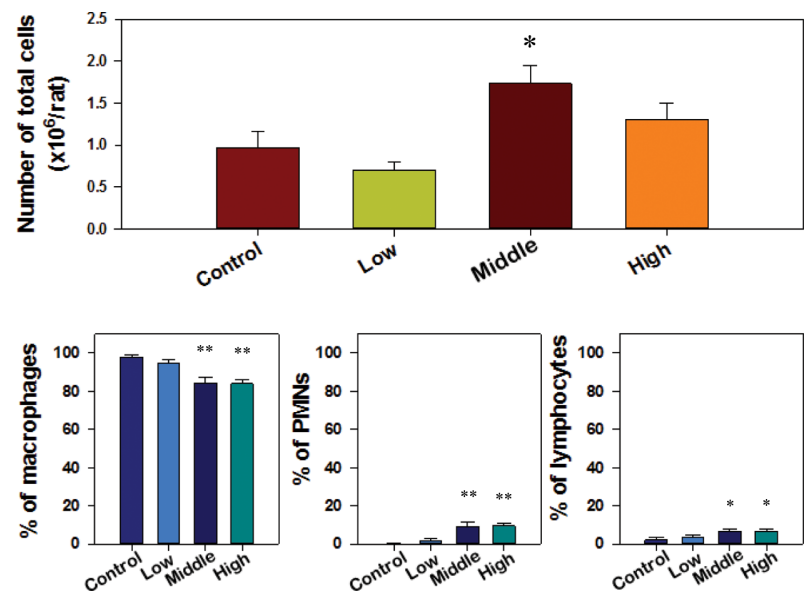

Fig. 5. Effects on the differential cell counts of bronchoalveolar lavaged cells in rats exposed to didecyldimethylammonium chloride (DDAC). Error bars indicate standard error. "Significantly different when compared to the control group, $P<0.05$. ${ }^{* *}$ Significantly different when compared to the control group, $P<0.01$.

age indicators, in the BAL fluid were confirmed to have not significantly been increased from exposure to DDAC (Table 2). The numbers of total white blood cells and neutrophils in the blood increased in exposed male rats for the middle $\left(0.36 \pm 0.20 \mathrm{mg} / \mathrm{m}^{3}\right)$ and high $\left(1.41 \pm 0.71 \mathrm{mg} / \mathrm{m}^{3}\right)$ groups (Table 3 ).

Lung weight was confirmed to have increased from exposure to DDAC. An increase in absolute lung weight was observed only in the female middle $\left(0.36 \pm 0.20 \mathrm{mg} / \mathrm{m}^{3}\right)$ group. However, relative lung weight was most prominent in the high $\left(1.41 \pm 0.71 \mathrm{mg} / \mathrm{m}^{3}\right)$ group because body weight significantly decreased only in the high $\left(1.41 \pm 0.71 \mathrm{mg} / \mathrm{m}^{3}\right)$ group. The relative weight of the males' left lungs increased by $7.4 \%$ in the middle $\left(0.36 \pm 0.20 \mathrm{mg} / \mathrm{m}^{3}\right)$ group and $22.0 \%$ in the high $\left(1.41 \pm 0.71 \mathrm{mg} / \mathrm{m}^{3}\right)$ group. Those of the females increased by $21.3 \%$ in the middle $(0.36 \pm 0.20 \mathrm{mg} /$ $\left.\mathrm{m}^{3}\right)$ group and $31.5 \%$ in the high $\left(1.41 \pm 0.71 \mathrm{mg} / \mathrm{m}^{3}\right)$ group (Table 4).

Inflammatory cell infiltration and interstitial pneumonia were partially observed at the middle $\left(0.36 \pm 0.20 \mathrm{mg} / \mathrm{m}^{3}\right)$ and high $\left(1.41 \pm 0.71 \mathrm{mg} / \mathrm{m}^{3}\right)$ groups in the histopathological findings. However, fibrosis was not induced by exposure to DDAC even though fibroblasts were found in some of the lungs of DDAC exposed rats (Fig. 6).

Table 2. Effects of didecyldimethylammonium chloride (DDAC) on the cell damage parameters in the bronchoalveolar lavage fluid

\begin{tabular}{|c|c|c|c|c|}
\hline & Control & Low & Middle & High \\
\hline ALB (mg/dL) & $0.00 \pm 0.001$ & $0.00 \pm 0.002$ & $0.00 \pm 0.002$ & $0.01 \pm 0.005$ \\
\hline LDH (IU/L) & $16.14 \pm 13.27$ & $27.13 \pm 35.25$ & $20.84 \pm 11.72$ & $21.81 \pm 15.61$ \\
\hline
\end{tabular}

ALB, albumin; LDH, Lactate dehydrogenase.

Values were presented as mean \pm standard deviation $(n=5)$. No statistically significant differences were found between rats in the control group and the rats exposed to DDAC. 
Table 3. Effects of didecyldimethylammonium chloride (DDAC) on the hematological parameters

\begin{tabular}{clcccc}
\hline \hline Sex & Parameters & Control & Low & Middle & High \\
\hline \multirow{6}{*}{ Male } & WBC $(\mathrm{K} / \mu \mathrm{L})$ & $5.12 \pm 0.80$ & $6.20 \pm 1.09$ & $6.31 \pm 0.97^{*}$ & $6.04 \pm 0.80^{*}$ \\
& NE $(\mathrm{K} / \mu \mathrm{L})$ & $1.46 \pm 0.47$ & $1.98 \pm 0.44^{*}$ & $2.09 \pm 0.38^{*}$ & $1.98 \pm 0.30^{*}$ \\
& $\mathrm{LY}(\mathrm{K} / \mu \mathrm{L})$ & $3.39 \pm 0.76$ & $4.00 \pm 0.85$ & $3.99 \pm 0.86$ & $3.77 \pm 0.63$ \\
& $\mathrm{MO}(\mathrm{K} / \mu \mathrm{L})$ & $0.23 \pm 0.14$ & $0.18 \pm 0.08$ & $0.18 \pm 0.09$ & $0.23 \pm 0.07$ \\
& EO $(\mathrm{K} / \mu \mathrm{L})$ & $0.02 \pm 0.01$ & $0.05 \pm 0.02^{*}$ & $0.05 \pm 0.02^{*}$ & $0.06 \pm 0.02^{*}$ \\
& $\mathrm{BA}(\mathrm{K} / ?)$ & $0.00 \pm 0.01$ & $0.00 \pm 0.00$ & $0.00 \pm 0.00$ & $0.00 \pm 0.00$ \\
\hline \multirow{5}{*}{ Female } & $\mathrm{WBC}(\mathrm{K} / \mu \mathrm{L})$ & $5.76 \pm 1.01$ & $4.76 \pm 0.75$ & $5.18 \pm 1.02$ & $5.12 \pm 1.24$ \\
& $\mathrm{NE}(\mathrm{K} / \mu \mathrm{L})$ & $1.48 \pm 0.27$ & $1.43 \pm 0.50$ & $1.28 \pm 0.43$ & $1.23 \pm 0.33$ \\
& $\mathrm{LY}(\mathrm{K} / \mu \mathrm{L})$ & $3.98 \pm 0.96$ & $4.40 \pm 0.49$ & $3.63 \pm 0.68$ & $3.63 \pm 0.95$ \\
& $\mathrm{MO}(\mathrm{K} / \mu \mathrm{L})$ & $0.25 \pm 0.06$ & $0.21 \pm 0.06$ & $0.23 \pm 0.08$ & $0.21 \pm 0.07$ \\
& $\mathrm{EO}(\mathrm{K} / \mu \mathrm{L})$ & $0.05 \pm 0.02$ & $0.03 \pm 0.01$ & $0.04 \pm 0.02$ & $0.05 \pm 0.02$ \\
\hline
\end{tabular}

WBC, white blood cell; NE, neutrophil; LY, lymphocyte; MO, monocyte; EO, eosinophil; BA, basophil.

Values were presented as mean \pm standard deviation.

"Significantly different when compared to the control group, $P<0.05$.

Table 4. Effects of didecyldimethylammonium chloride (DDAC) on lung weight

\begin{tabular}{|c|c|c|c|c|c|}
\hline Sex & Organ & Control & Low & Middle & High \\
\hline \multicolumn{6}{|c|}{ Absolute weight (g) } \\
\hline \multirow{2}{*}{ Male } & Lung L & $0.467 \pm 0.038$ & $0.470 \pm 0.034$ & $0.499 \pm 0.051$ & $0.511 \pm 0.041$ \\
\hline & Lung $\mathrm{R}$ & $1.338 \pm 0.196$ & $1.351 \pm 0.114$ & $1.387 \pm 0.104$ & $1.373 \pm 0.135$ \\
\hline \multirow{2}{*}{ Female } & Lung L & $0.335 \pm 0.036$ & $0.342 \pm 0.029$ & $0.379 \pm 0.035^{*}$ & $0.371 \pm 0.049$ \\
\hline & Lung $\mathrm{R}$ & $0.600 \pm 0.052$ & $0.616 \pm 0.038$ & $0.671 \pm 0.061 *$ & $0.650 \pm 0.074$ \\
\hline \multicolumn{6}{|c|}{ Relative weight (g/100 g body weight) } \\
\hline \multirow{2}{*}{ Male } & Lung L & $0.106 \pm 0.009$ & $0.103 \pm 0.010$ & $0.116 \pm 0.011$ & $0.139 \pm 0.011^{* *}$ \\
\hline & Lung $\mathrm{R}$ & $0.305 \pm 0.046$ & $0.296 \pm 0.027$ & $0.322 \pm 0.017$ & $0.372 \pm 0.037 * *$ \\
\hline \multirow{2}{*}{ Female } & Lung L & $0.127 \pm 0.008$ & $0.137 \pm 0.007$ & $0.154 \pm 0.010^{* *}$ & $0.167 \pm 0.014^{* *}$ \\
\hline & Lung $\mathrm{R}$ & $0.227 \pm 0.015$ & $0.248 \pm 0.016$ & $0.272 \pm 0.019 * *$ & $0.293 \pm 0.016^{* *}$ \\
\hline
\end{tabular}

$\mathrm{L}$, left; $\mathrm{R}$, right.

Values were presented as mean \pm standard deviation $(n=10)$.

"Significantly different when compared to the control group, $P<0.05$.

** Significantly different when compared to the control group, $P<0.01$.

\section{DISCUSSION}

Didecyldimethylammonium chloride (DDAC) is an antiseptic chemical that is used in many biocidal applications for its rapid killing ability. This ability is due to a very strong initial adsorption to cell walls (9). Products containing DDAC are formulated as liquid ready-to-use soluble concentrates and the content ratio of DDAC in various enduse products ranges from $0.08 \%$ to $80 \%$ DDAC. However, there are concerns regarding the effects that DDAC has on the health of humans that have been exposed to DDAC via dietary, dermal and inhalation pathways. DDAC is known to especially cause moderate irritation to the eyes and skin of humans and people exposed to DDAC as an occupational hazard have been reported to have induced contact dermatitis $(11,12)$.

In the mice exposure experiment, DDAC was confirmed to cause infertility and birth defects (10), and also caused alveolar cell injuries, inflammation, interstitial pneumonia and fibrosis in rodent lungs $(1,7)$. According to EPA (United States Environmental Protection Agency) risk assessments, the acute toxicity data of DDAC is $238 \mathrm{mg} / \mathrm{Kg}$ for rats (LD50, purity $80 \%$ ), $0.07 \mathrm{mg} / \mathrm{L}$ for rats (LC50, purity not reported) and classified as category I for skin and eye irritation. In the 90-day rat oral feeding study, higher incidents of glycogen depletion in the liver and contracted spleens were observed, and 90-day dermal toxicity testing in rats showed no systemic toxicity or clinical and gross findings (6). Gomi et al. (9) reported that DDAC is absorbed physiochemically through hydrophobic interactions into the cell membrane of S.aureus, where it can react with lipids and cause significant damage to the structure and function of the membrane examined in his study. This may one of the reasons for the toxic effect of DDAC on cells and organs. 


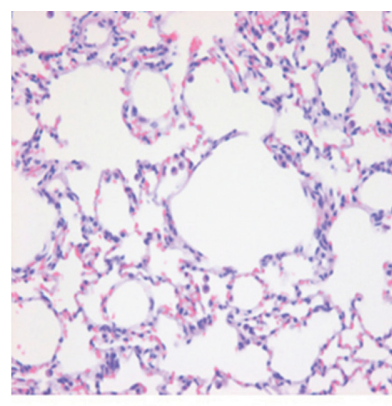

NORMAL $\times 400$

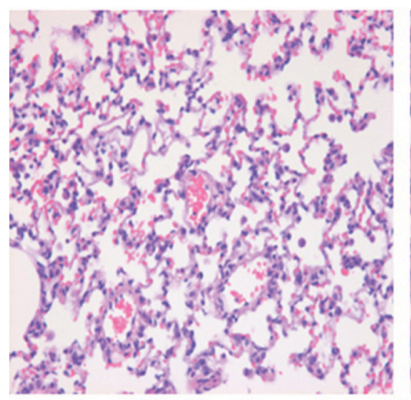

MIDDLE x400

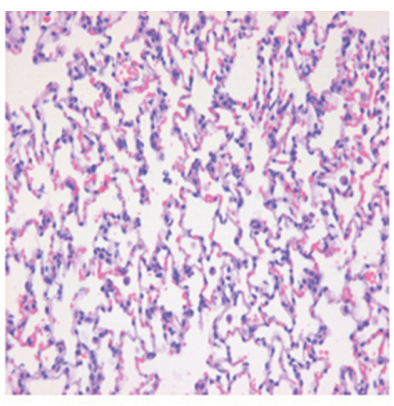

LOW $\times 400$

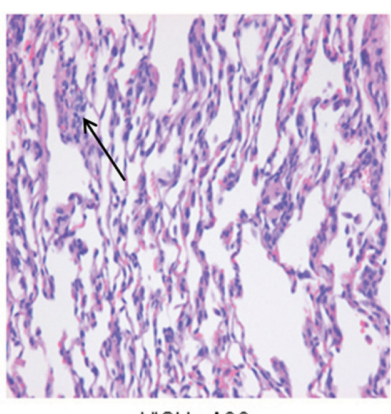

$\mathrm{H} \mathrm{GH} \times 400$
Fig. 6. Histopathology of the lungs exposed to didecyldimethylammonium chloride (DDAC). The arrow in the high dose group indicates the migration of inflammatory cells and the thickening of the alveolar wall.

Ohnuma et al. (1) reported that exposure to $1,500 \mu \mathrm{g} / \mathrm{kg}$ of DDAC through intratracheal instillation caused severe morbidity with pulmonary congestive edema and that exposure to $150 \mu \mathrm{g} / \mathrm{kg}$ of DDAC caused pulmonary injury whereas exposure to $15 \mu \mathrm{g} / \mathrm{kg}$ of DDAC did not show any visible change in mice. From this report, it can be suggested that DDAC might be approximately 300 times more toxic when administered intratracheally rather than orally. Therefore, we expected that DDAC might also cause severe lung damage when inhaled via the respiratory system. The equivalent concentration of intratracheally instilled $1,500 \mu \mathrm{g} / \mathrm{kg}$ for a mouse was calculated to be $3.9 \mathrm{mg} / \mathrm{m}^{3}$ assuming that the respiratory volume for a mouse is $0.035 \mathrm{~m}^{3} /$ day and body weight is $0.023 \mathrm{~kg}$. Therefore, $0.15 \mathrm{mg} / \mathrm{m}^{3}$ to $3.6 \mathrm{mg} /$ $\mathrm{m}^{3}$ of DDAC was exposed to the rats for 2 weeks to confirm the toxicity of DDAC on rat lungs in a previous study. The main changes observes in this research were the changes in body weight and in the lungs and based on these observations the no observed adverse effect level (NOAEL) for DDAC was suggested to be $0.15 \mathrm{mg} / \mathrm{m}^{3}$. However, the effects were confirmed to be relatively mild, and severe symptoms such as proteinosis and/or fibrosis were not identified (7). Therefore, we exposed the rats to DDAC for 13 weeks and attempted to make observations to discover any adverse effects of DDAC on the lungs, which would be easier to observe due to the increase in severity of the symptoms caused by longer exposure periods.
Similar to the results of our previous study, the effects of DDAC on body weight changes were obvious. The mean body weight was observed to be lower by up to $30 \%$ in the male high $\left(1.41 \pm 0.71 \mathrm{mg} / \mathrm{m}^{3}\right)$ concentration group. Food consumption was also observed to be significantly affected by exposure to DDAC as food consumption decreased approximately by $5 \%$ in the middle $\left(0.36 \pm 0.20 \mathrm{mg} / \mathrm{m}^{3}\right)$ group and by $20 \%$ in the high $\left(1.41 \pm 0.71 \mathrm{mg} / \mathrm{m}^{3}\right)$ group. It can be inferred that the body weight change of animals is related to food consumption, but the reason cannot clearly be extracted from the results of the research.

The effects observed on the respiratory system after exposure to DDAC were not like those in Ohnuma's study (1). Only mild to moderate lung damage was identified in our study. The ratio of PMNs increased only to approximately $10 \%$. The lung weight of the rats were shown to have increased by more than $30 \%$ in the case of a high $(1.41 \pm$ $0.71 \mathrm{mg} / \mathrm{m}^{3}$ ) concentration of DDAC. Migration of inflammatory cells and thickening of alveolar walls were found in the middle $\left(0.36 \pm 0.20 \mathrm{mg} / \mathrm{m}^{3}\right)$ and high $(1.41 \pm 0.71 \mathrm{mg} /$ $\mathrm{m}^{3}$ ) groups. However, severe histopathological symptoms were not confirmed in our study. Severe lung symptoms might have been identified if pregnant and postpartum rats were exposed to DDAC, but there were no severe symptoms observed in the normal young-adult rats $(3,4)$.

Other general items including blood chemistry, hematology, organ weight (of the thymus, heart, adrenal gland, ovary, kidney, spleen, liver, brain) and histopathology (of the liver, kidney, heart, etc.) were examined through a general repeated toxicity test evaluation, but it was confirmed that there was no dependency on dosage or on test substance. In conclusion, the main factors influencing DDAC inhalation exposure were confirmed to be changes in body weight lung weight, and based on this it is considered that the NOAEL for DDAC is $0.11 \mathrm{mg} / \mathrm{m}^{3}$ for 13 weeks of repeated inhalation exposure.

\section{REFERENCES}

1. Ohnuma, A., Yoshida, T., Tajima, H., Fukuyama, T., Hayashi, K., Yamaguchi, S., Ohtsuka, R., Sasaki, J., Fukumori, J., Tomita, M., Kojima, S., Takahashi, N., Takeuchi, Y., Kuwahara, M., Takeda, M., Kosaka, T., Nakashima, N. and Harada, T. (2010) Didecylmethylammonium chloride induces pulmonary inflammation and fibrosis in mice. Exp. Toxicol. Pathol., 62, 643-651.

2. United States Environmental Protection Agency (2006) Reregistration Eligibility Decision for Aliphatic Alkyl Quaternaries (DDAC), EPA739-R-06-008, United States Environmental Protection Agency, Washington, D.C.

3. Kim, K.W., Ahn, K., Yang, H.J., Lee, S., Park, J.D., Kim, W.K., Kim, J.T., Kim, H.H., Rha, Y.H., Park, Y.M., Sohn, M.H., Oh, J.W., Lee, H.R., Lim, D.H., Choung, J.T., Han, M.Y., Lee, E., Kim, H.Y., Seo, J.H., Kim, B.J., Cho, Y.A., Do, K.H., Kim, S.A., Jang, S.J., Lee, M.S., Kim, H.J., Kwon, G.Y., 
Park, J.H., Gwack, J., Youn, S.K., Kwon, J.W., Jun, B.Y., Pyun, B.Y. and Hong, S.J. (2014) Humidifier disinfectant associated children's interstitial lung disease. Am. J. Respir. Crit. Care Med., 189, 48-56.

4. Yang, H.J., Kim, H.J., Yu, J., Lee, E., Jung, Y.H., Kim, H.Y., Seo, J.H., Kwon, G.Y., Park, J.H., Gwack, J., Youn, S.K., Kwon, J.W., Jun, B.Y., Kim, K.W., Ahn, K., Lee, S.Y., Park, J.D., Kwon, J.W., Kim, B.J., Lee, M.S., Do, K.H., Jang, S.J., Pyun, B.Y. and Hong, S.J. (2013) Inhalation toxicity of humidifier disinfectants as a risk factor of children's interstitial lung disease in Korea: a case-control study. PLoS ONE, 8, e64430.

5. Wikipedia (2014) Biocide [cited 2014 Apr 11]. Available from: http://en.wikipedia.org/wiki/Biocide/.

6. United State Environmental Protection Agency (2006) Draft Didecyl Dimethly Ammonium Chloride (DDAC) Risk Assessment, Office of Pesticide Programs Antimicrobials Division, Arlington, V.A., pp. 9-32.

7. Lim, C.H. and Chung, Y.H. (2014) Effects of Didecyldimethylammonium chloride on sprague-dawley rats after two weeks of inhalation exposure. Toxicol. Res., 30, 205-210.

8. Yang, J.S., Choi, S.B., Park, S.Y. and Lee, S.B. (2012) Analy- sis of didecyldimethylammonium chloride (DDAC) aerosol in inhalation chamber. Anal. Sci. Technol., 25, 307-312.

9. Gomi, M., Osaki, Y., Mori, M. and Sakagami, Y. (2012) Synergistic bacterial effects of a sublethal concentration of didecyldimethylammonium chloride (DDAC) and low concentrations of nonionic surfactants against Staphylococcus aureus. Biocontrol Sci., 17, 175-181.

10. Wikipedia (2015) Didecyldimethylammonium chloride (DDAC) [cited 2016 Jan 05]. Available from: http://en.wikipedia.org/ wiki/Didecyldimethylammonium chloride/.

11. Dejobert, Y., Martin, P., Piette, F., Thomas, P. and Bergoend, H. (1997) Contact dermatitis from didecyldimethylammonium chloride and bis-(aminopropyl)-lauryl amine in a detergent-disinfectant used in hospital. Contact Derm., 37, 95-96.

12. Geier, J., Lessmann, H., Krautheim, A. and Fuchs, T. (2013) Air borne allergic contact dermatitis caused by didecyldimethylammonium chloride in a geriatric nurse. Contact Derm., 68, 123-125.

13. Organization for Economic Cooperation and Development (2009) OECD guidelines for the testing of chemicals. Test guideline 413. Subchronic inhalation toxicity: 90-day study, OECD, Paris. 